\title{
LA COMPETENCIA EXCLUSIVA DEL ESTADO SOBRE ORDENACIÓN DE LOS REGISTROS E INSTRUMENTOS PÚBLICOS. ALGUNAS REFLEXIONES TRAS LA STC 7/2019, DE 17 DE ENERO, SOBRE EL REGISTRO ELECTRÓNICO DE VOLUNTADES DIGITALES DE CATALUÑA
}

The State's exclusive power over ordinance of public registries and instruments. Some reflections after the STC $7 / 2019$, of January 7 th, on the electronic registry of digital wills of Catalonia

CARMEN PÉREZ DE ONTIVEROS BAQUERO Universidad de Las Palmas de Gran Canaria carmen.perezontiveros@ulpgc.es

Cómo citar/Citation

Pérez de Ontiveros Baquero, C. (2019). La competencia exclusiva del Estado sobre ordenación de los registros e instrumentos públicos. Algunas reflexiones tras la STC 7/2019, de 17 de enero, sobre el registro electrónico de voluntades digitales de Cataluña. Derecho Privado y Constitución, 35, 87-123. doi: https://doi.org/10.18042/cepc/dpc.35.03

(Recepción: 27/06/2019; aceptación tras revisión: 21/10/2019; publicación: 29/11/2019)

\section{Resumen}

La STC 7/2019, de 17 de enero, declara la inconstitucionalidad de determinados preceptos de la Ley 10/2017, de 27 de junio, de las voluntades digitales y de modificación de los Libros Segundo y Cuarto del CC de Cataluña, en concreto, de aquellos artículos en los que se establece la creación del registro electrónico de voluntades digitales. En ella, el TC dice aplicar su propia doctrina consolidada sobre el alcance de la competencia sobre la ordenación de los registros e instrumentos públi- 
cos que se atribuye al Estado ex art. 149.1.8 de la CE. En el presente artículo, y sobre la base de lo que constituye el objeto del pronunciamiento, las llamadas voluntades digitales, se analiza esta doctrina y su aplicación concreta, teniendo en cuenta que en ella se emite un voto particular en el que se exterioriza, entre otras cosas, cierta falta de coherencia en esta.

\section{Palabras clave}

Ordenación de los registros e instrumentos públicos; competencia estatal.

\section{Abstract}

The Constitutional Court Ruling "STC 7/2019 of 17 january" declares the unconstitutionality of certain provisions of the Law 10/2017, of 27 june, on digital wills and of modification of Second and Fourth Books of the Civil Code of Catalonya, in particular, of those articles that establish the creation of electronic registry of digital wills. In this ruling, the Constitutional Court applies its own consolidated doctrine on the competence scope in relation to the organisation of the public registries and instruments, attributed to the State according to art. 149.1.8 of te E.C. In the current article, and based on the purpose of the declaration, the so called digital wills, this doctrine and its concrete application are analysed, taking into account that a particular vote is issued through it, which shows, among other things, certain lack of coherence.

\section{Keywords}

Organisation of the public Registries and Instruments; State compete. 


\section{SUMARIO}

I. INTRODUCCIÓN. II. LA DELIMITACIÓN DE LA COMPETENCIA SOBRE LA ORDENACIÓN DE LOS REGISTROS E INSTRUMENTOS PÚBLICOS EN LA DOCTRINA DEL TRIBUNAL CONSTITUCIONAL. III. DISPOSICIÓN MORTIS CAUSA DEL PATRIMONIO DIGITAL. EL REGISTRO ELECTRÓNICO DE VOLUNTADES DIGITALES Y LA COMPETENCIA ESTATAL SOBRE ORDENACIÓN DE LOS REGISTROS E INSTRUMENTOS PÚBLICOS: 1. Las disposiciones sobre el contenido digital para el caso de fallecimiento. Su ordenación jurídica. 2. El registro electrónico de voluntades digitales de Cataluña y la competencia estatal sobre ordenación de los registros e instrumentos públicos. La STC 7/2019, de 17 de enero. IV. A MODO DE CONCLUSIÓN. BIBLIOGRAFÍA.

\section{INTRODUCCIÓN}

Durante los cuarenta años de vigencia de nuestra Constitución, no han sido escasas las ocasiones en las que el TC ha tenido que pronunciarse sobre el alcance de la competencia que, con carácter exclusivo, atribuye al Estado el art. 149.1.8 de la Norma Suprema sobre «ordenación de los registros e instrumentos públicos». La lectura de sus últimos pronunciamientos pone de manifiesto la aceptación por el propio Tribunal de una doctrina que entiende consolidada acerca de la distribución de competencias en esta materia entre el Estado y las CC. AA, habida cuenta que las CC. AA. pueden, en el ejercicio de sus competencias, y como así se ha admitido, crear registros propios, como instrumentos administrativos de publicidad y control.

Dicha doctrina constitucional viene claramente sintetizada en la Sentencia 7/2019, de 17 de enero, sobre el registro electrónico de voluntades digitales de Cataluña, en la que se resuelve sobre el recurso de inconstitucionalidad interpuesto por el presidente del Gobierno en relación con diversos preceptos de la Ley 10/2017, de 27 de junio, de las voluntades digitales y de modificación de los Libros Segundo y Cuarto del CC de Cataluña. En dicha resolución se declara la nulidad de los preceptos autonómicos relativos a inscripción de las voluntades digitales, fundamentada en la vulneración del art. 149.1.8 de la $\mathrm{CE}$, al entender que el legislador autonómico había procedido, mediante la creación de un registro en que han de inscribirse tales voluntades, a invadir la competencia exclusiva del Estado en materia de ordenación de los registros e instrumentos públicos. 
La importancia de esta resolución deriva no solo del hecho de que en ella se contempla una síntesis de la doctrina constitucional vigente sobre esta materia, sino también del hecho de que, frente a la decisión mayoritaria del Tribunal, consta el voto particular de una de sus magistradas ${ }^{1}$. En su defensa, y frente a los argumentos expuestos en ella, quien lo suscribe expone algunas razones relevantes, entre las que destacan las dificultades que ocasiona la admisión de esta doctrina, al contrastarla con la vigencia y constitucionalidad de determinados registros creados por las CC. AA. en el ejercicio de sus competencias. De la misma forma, cabe destacar la existencia de alguna posición doctrinal en clara discrepancia con la solución admitida por el TC, al entender que el registro creado en la ley autonómica tiene carácter visiblemente administrativo².

Desde el análisis de algunos de los problemas que derivan de la ordenación jurídica del destino de los llamados «bienes digitales» al fallecimiento de quien era su titular, lo pretendido en este estudio, y dentro de su reducido ámbito, es una aproximación a la doctrina contenida en algunas importantes SSTC, en las que se aborda el alcance de la competencia estatal en esta materia, su delimitación con la que corresponde a las CC. AA. en el ejercicio de las que les son propias, y su apreciación con referencia concreta a lo que constituye el objeto específico del registro sobre el que se pronuncia el TC en la Sentencia 7/2019, de 17 de enero. Todo ello, en la necesidad de constatar si esta doctrina constitucional avala las voces discordantes que se alzan en atención a una posible falta de sintonía y uniformidad, en su concreta aplicación a las diferentes materias cuyo control y publicidad exigen la creación de un registro específico.

Por razones de espacio, dejo conscientemente al margen de este estudio las relevantes cuestiones que suscita lo dispuesto en la reciente Ley Orgánica 3/2018, de 5 de diciembre, de Protección de Datos, sobre esta materia, cuestión a la que solo me remitiré de forma tangencial a la hora de completar el marco normativo al que han de circunscribirse los problemas tratados.

\section{LA DELIMITACIÓN DE LA COMPETENCIA SOBRE LA ORDENACIÓN DE LOS REGISTROS E INSTRUMENTOS PÚBLICOS EN LA DOCTRINA DEL TRIBUNAL CONSTITUCIONAL}

Como he señalado, la finalidad de este estudio requiere una previa aproximación a la doctrina del TC sobre esta competencia estatal ex 148.1.8 CE, centrándonos exclusivamente en lo relativo a la ordenación de los registros.

\footnotetext{
1 La magistrada Encarnación Roca i Trias.

2 En este sentido, Solé Resina (2018: 434 y ss.).
} 
Para ello, me remitiré a algunas de las sentencias dictadas, atendida su especial relevancia.

En orden a esta delimitación competencial, el TC adopta como premisa básica en sus sentencias que los registros a los que se refiere el art. 149.1.8 son los civiles, ya que la reserva se aúna a la legislación civil, quedando, por tanto, fuera de esta competencia los registros mercantiles, para los que la competencia exclusiva del Estado ha de subsumirse en el art. 149.1.6 CE³

También el TC ha señalado reiteradamente que las CC. AA., en el ejercicio de sus competencias, pueden crear registros de carácter administrativo, que en este caso se ligan a la materia que es objeto de competencia propia ${ }^{4}$. Desde esta perspectiva, el propio TC ha ido incardinando en algunas de sus resoluciones los correspondientes registros en la materia en la que habrían de subsumirse. Entendiendo, a su vez, que el Estado puede establecer los registros de carácter administrativo que estime necesario para ejercer competencias distintas a las establecidas en el art. 149.1.8 CE, si bien al regular el régimen jurídico de estos registros debe respetar las competencias de ejecución que hayan asumido las CC. AA. en relación con cada materia. Y es también posible que el Estado pueda crear un registro único que garantice la centralización de todos los datos a los estrictos efectos de información y publicidad.

En cuanto a su alcance, el TC ha precisado que la competencia de ordenación de los registros públicos prevista en el art. 149.1.8 CE comprende la íntegra regulación de la materia, ya sea a través de normas legales o de disposi-

STC 72/1983, de 29 de julio (FJ 8).

4 En este sentido, puede leerse en la STC 209/2014, de 18 diciembre (FJ 5): «Según hemos recordado en la STC 81/2013, de 11 de abril, FJ 5, la posibilidad de que las Comunidades Autónomas, en el ejercicio de sus competencias, creen registros administrativos "ha sido admitida con naturalidad por la doctrina constitucional desde las SSTC 32/1983, de 28 de abril, y 87/1985, de 16 de julio”. En la doctrina del Tribunal está igualmente subrayado que, salvo los registros de carácter civil y el Registro mercantil, que sigue a la competencia del Estado en materia de legislación mercantil (art. 149.1.6 CE), no es el título competencial del art. 149.1.8 CE (relativo a "registros e instrumentos públicos"), sino la materia en cada caso comprometida la que determina la distribución de competencias para la ordenación del correspondiente registro administrativo (SSTC 197/1996, de 28 de noviembre, FJ 12; 103/1999, de 3 de junio; FJ 3; y 134/2006, de 27 de abril, FJ 8). De modo congruente, en el presente asunto es la compatibilidad con el título competencial relativo a las bases de la ordenación del crédito del art. 149.1.11 CE del previsto en el art. 30.1.5 EAG lo que debemos observar ahora». 
ciones de rango reglamentario, pudiendo asumir las CC. AA. en esta materia competencias meramente ejecutivas 5 .

Con tales premisas, puede considerarse que el primero de los pronunciamientos importantes del TC sobre el alcance de la competencia en esta materia se contiene en la STC 71/1983, de 29 de julio $^{6}$, en la que el Tribunal se pronuncia sobre la titularidad del Catálogo de Montes de Utilidad Pública; en concreto, sobre si este debía incluirse en la competencia sobre montes, asumida por la Generalitat de Cataluña, o bien en el ámbito de la competencia estatal sobre ordenación de los registros e instrumentos públicos. A tenor de los argumentos expuestos por el abogado del Estado, y en cuanto ahora interesa, la competencia a favor del Estado quedaba avalada por el hecho de que el citado catálogo tenía la naturaleza de un registro público (art. 6 de la Ley de Montes y 38 de su Reglamento, pese a que ambas normas referían su carácter administrativo), y, en que, pese a tal carácter administrativo, desplegaba importantes efectos jurídicos en el ámbito del derecho civil, entre los que cita la presunción posesoria a favor de la entidad a la que el catálogo asigne su pertenencia o la fijación de un plazo de prescripción de treinta años.

El TC no lo entiende así, admitiendo que los registros a los que se refiere el art. 149.1.8 de la CE son los «referentes fundamentalmente a materias de Derecho privado, como se infiere de su contexto, y no a otros Registros que, como el Catálogo, aunque tengan repercusiones en ese campo del Derecho, tiene por objeto materias ajenas a él, cual es un aspecto de la legislación sobre montes» (FJ 2), por lo que la competencia habría de subsumirla en el ámbito de la asumida por la comunidad autónoma sobre «montes».

Por tanto, para el TC, el criterio de la materia que es objeto de registro resulta relevante para determinar la competencia, quedando relevado el de los efectos o posibles repercusiones en derecho privado a un segundo plano, argumentación que ya fue criticada en su día con razonamientos convincentes ${ }^{7}$.

Sin embargo, con posterioridad, el TC matiza este criterio en la Sentencia 284/1993, de 30 de septiembre, en el recurso interpuesto frente a determinados preceptos de la Ley del Parlamento de Cataluña 23/1991, de 29 de

5 Así, entre otras, SSTC 82/1984, de 20 de julio (FJ 2), y 67/2017, de 25 de mayo (FJ 3).

6 RTC 1983/71.

7 En este sentido, Marín López (1994: 119), con referencia concreta a los registros de bienes, entiende que el criterio de la «materia» es inservible, o, en el mejor de los casos, «insuficiente» por sí solo, para discriminar aquellos registros cuya ordenación compete al Estado, siendo necesario complementar este con el relativo a los efectos que produce la inscripción en el tráfico jurídico civil. 
noviembre, de Comercio Interior ${ }^{8}$. En este caso, el TC entiende que el registro que crea la norma es de naturaleza administrativa, habida cuenta de las finalidades perseguidas por su institución, y el carácter puramente administrativo de la infracción y sanción previstas para el caso de incumplimiento del deber de inscripción, incumplimiento que no generaba consecuencia alguna en las relaciones inter privatos.

Junto con ello, y atendida la materia a la que afecta, resulta importante referir la doctrina del TC respecto del alcance de la competencia de las CC. AA. en relación con los registros de parejas de hecho o uniones estables, en la que debe destacarse la naturaleza que atribuye a estos registros, a los que configura de carácter puramente administrativo, admitiendo que su inscripción en él lo es a meros efectos de publicidad.

Así, la STC 81/2013, de 11 de abril ${ }^{9}$, resuelve la cuestión de constitucionalidad planteada por la Sala de lo Contencioso-Administrativo del TSJ de Madrid respecto a determinados preceptos de la Ley de la Asamblea de Madrid 11/2001, de 19 de diciembre, de uniones de hecho.

En este caso, el TC declara la falta de adecuación a la CE de los arts. 4 y 5 de la ley, atendido al hecho de que vulneran la competencia que en legislación civil ostenta el Estado al amparo del art. 149.1.8 CE. Así, entiende que, examinando lo dispuesto en el art. 4, es evidente que describe determinadas prescripciones que han de observar los pactos suscritos por los integrantes de la unión de hecho dirigidos a regir sus relaciones económicas y patrimoniales, tanto constante la convivencia como con ocasión de su cese, por lo que estas constituyen reglas de derecho privado que entran de lleno dentro del ámbito de la competencia estatal. Mientras que la falta de adecuación a la CE del art. 5 deriva de su conexión con el precepto anterior, ya que se trata de una norma meramente procedimental relativa a la inscripción en el registro de uniones de hecho de los pactos previstos en el art. 4.

En lo que ahora interesa, declara la adecuación a la CE de lo dispuesto en su art. 3, en donde, bajo la rúbrica general «Acreditación», disponía que las uniones de hecho a las que se refiere la ley producirán sus efectos desde la fecha de la inscripción en el Registro de las Uniones de Hecho, previa acreditación de los requisitos a que se refiere el art. 1, en expediente contradictorio ante el encargado de un registro que se regularía reglamentariamente. Estableciendo, finalmente, que la existencia de la unión de hecho se acreditará mediante certificación del encargado del registro.

En este caso, el TC (FJ 5) sostiene:

$8 \quad$ RTC 284/1993 (FJ 6).

9 RTC $81 / 2013$. 
Descartado ya, de acuerdo con lo razonado en el fundamento jurídico precedente, que el registro despliegue su eficacia en el ámbito de las relaciones personales y patrimoniales de los integrantes de la unión de hecho, pues hemos dejado sentado que la Comunidad Autónoma carece de competencias para establecerlo así, resulta que el mismo se limita a publicitar un hecho, la existencia de la previa unión de hecho a fin de atribuirles determinada eficacia en ámbitos de competencia propia de la Comunidad de Madrid y, por tanto, sin incidir en la legislación civil ni, por lo mismo, en la competencia estatal relativa a la ordenación de los registros del art. 149.1.8 CE. A tal fin la inscripción en el registro que se contempla en el art. 3 tiene por única finalidad [...] la acreditación de una situación de hecho, de modo que resulte posible aplicar el régimen jurídico que, en el ámbito de competencias autonómico, el legislador territorial haya considerado oportuno establecer, sin afectar a facetas propias de las relaciones personales o patrimoniales de los integrantes de la unión de hecho.

Discrepa de esta solución el voto particular que formula el magistrado don Manuel Aragón Reyes, al que se adhiere el magistrado don Andrés Ollero Tassara, fundamentándolo, en cuanto nos interesa, en que no es suficiente con declarar que la regulación establecida en el art. 3 no puede incidir en la legislación civil, sobre la que la Comunidad de Madrid carece de competencias, sino que debió haberse declarado también en la Sentencia — para salvar la constitucionalidad del precepto sin detrimento de las competencias estatales- que la inscripción de la unión de hecho en el registro de uniones de hecho de la Comunidad de Madrid solo podrá producir efectos en el ámbito de las competencias de esta comunidad autónoma, llevando tal interpretación al fallo.

Sobre esta misma materia se pronuncia también la STC 93/2013, de 23 de abril ${ }^{10}$, en el recurso interpuesto frente a la Ley Foral 6/2000, de 3 de julio, para la igualdad jurídica de las parejas estables. Aun cuando dicho pronunciamiento es meramente tangencial, en su FJ 10, el TC avala la posibilidad de que los ayuntamientos de Navarra y su Gobierno puedan crear los oportunos registros para facilitar a través de su inscripción voluntaria la prueba de su constitución.

El alcance de la competencia estatal sobre ordenación de los registros e instrumentos públicos constituye también la ratio decidendi de la STC 4/2014, de 16 de enero ${ }^{11}$, en el recurso interpuesto frente a la Ley del Parlamento de Cataluña 5/2009, de 28 de abril. En este caso, la controversia giraba principalmente en torno a la aplicación al caso concreto de la doctrina del TC sobre la delimitación del título competencial «ordenación de los re-

10 RTC 93/2013.

11 RTC 4/2014 (FJ 3). 
gistros públicos e instrumentos públicos» del art. 149.1.8 CE versus el título competencial recogido en el art. 147.2 del EA de Cataluña, que atribuía a la Generalitat la competencia exclusiva en materia de régimen de los recursos sobre la calificación de los títulos o las cláusulas concretas en materia de derecho catalán que deban tener acceso a un registro de la propiedad, mercantil o de bienes muebles de Cataluña. En este caso, el TC reitera en su integridad la doctrina contenida en su Sentencia 71/1983, de 29 de julio, entendiendo que los registros sobre los que Estado ostenta competencia exclusiva son los referentes fundamentalmente a materias de derecho privado, como se infiere de su contexto, y no otros registros que, aunque tengan repercusiones en ese campo del derecho, tienen por objeto materias ajenas a él.

Con posterioridad, en la STC $11 / 2015$, de 5 de febrero $^{12}$, vuelve a plantear el alcance de la competencia estatal sobre ordenación de los registros. En ella se resuelve el recurso de inconstitucionalidad interpuesto por el Gobierno de Canarias frente a la Ley 35/2011, de 4 de octubre, sobre titularidad compartida de las explotaciones agrarias. En cuanto interesa, la impugnación afectaba al art. 6 de la citada norma, ya que dicho precepto establecía que para que la titularidad compartida de las explotaciones agrarias produzca todos sus efectos jurídicos, sería precisa su inscripción previa en el registro constituido al efecto por la correspondiente comunidad autónoma, estableciendo, por tanto, el carácter constitutivo de la inscripción.

En defensa de su constitucionalidad, el abogado del Estado entendía que los registros que se creen al amparo del precepto son fundamentalmente registros administrativos, argumentando que el hecho de que la inscripción en los registros autonómicos a los que se refiere el precepto impugnado pueda producir colateralmente alguna consecuencia o efecto jurídico en el ámbito del derecho privado, como los relativos a la administración, representación o responsabilidad reguladas en el art. 4, no es argumento suficiente para considerar que dicho registro deba ampararse en el título competencial del art. 149.1.8 CE, debiendo entenderse prevalente el del art. 149.1.13 CE.

Pues bien, el TC así lo entiende, y, declarando la constitucionalidad del precepto, nos dice en su FJ 3:

[...] los únicos efectos civiles que puede producir el régimen de titularidad agraria compartida son los relativos a la liquidación económica que tenga lugar a la extinción de aquella titularidad, que figuran regulados en el citado capítulo IV de la Ley, que, sin embargo, no son esenciales a la legislación civil, pues no modifican régimen económico matrimonial ni sucesorio alguno, así como tampoco las normas propias

12 RTC $11 / 2015$. 
de administración, representación y responsabilidad de la titularidad compartida establecidas en el artículo 4 de la Ley, que vienen referidas en todos los casos a la propia institución de la titularidad compartida, por lo que no puede entenderse que la materia regulada sea aquella a la que se refiere el art. 149.1.8 CE, como alega el Gobierno de Canarias.

Reiterando su doctrina contenida en resoluciones anteriores, al admitir que «no cabe entender sino que los registros a que dicha ordenación se refiere son exclusivamente los de carácter civil».

El TC parece destacar en este caso los efectos de carácter meramente administrativo que estaría llamada a producir la inscripción; así, señala en su FJ 6: «La inscripción en el registro de la Comunidad Autónoma no es sino un elemento que, junto al cumplimiento de otros requisitos que reglamentariamente se determinarán para cada tipo de beneficio que se instituya, opera como una condición previa para el otorgamiento de cualesquiera ayudas o beneficios por parte del Estado [...]».

Especial importancia tiene en este sentido la naturaleza administrativa que según el TC ha de atribuirse a los registros de asociaciones y fundaciones, materias incardinadas tradicionalmente en el ámbito del derecho civil.

El derecho fundamental de asociación se encuentra regulado en el art. 22 de la CE, por lo que su desarrollo debe efectuarse mediante ley orgánica. Pues bien, el TC, en la Sentencia 173/1998, de 23 de julio (FJ 5) ${ }^{13}$, entiende que la reserva de ley orgánica debe limitarse a la regulación de los aspectos esenciales del derecho fundamental considerado en abstracto, en tanto que se atribuye la regulación de la materia sobre la que se proyecta al legislador estatal o autonómico, con competencias sectoriales sobre la misma, según las reglas de distribución de competencias aplicables al sector sobre el que se concreta el derecho fundamental. Pero, junto con ello, el Estado goza de competencias ex art. 149.1.1 de la CE sobre la regulación de las condiciones básicas que garanticen la igualdad de todos los españoles en el ejercicio de los derechos y en el cumplimiento de los deberes constitucionales, que en materia de asociaciones sintetiza la STC 133/2006, de 27 de abril (FJ 4), y reitera la STC 135/2006, de 27 de abril (FJ 2) $)^{14}$.

Pues bien, sin entrar en el problema que suscita la inclusión de la materia «asociaciones» — si no toda, al menos en algunos de sus aspectos-, en el ámbito de la legislación civil, de competencia exclusiva del Estado ex art. 149.1.8

13 RTC $173 / 1998$.

14 RTC 13/2006 y RTC 135/2006. 
$\mathrm{CE}^{15}$, la subsunción de los registros de asociaciones en el ámbito de dicho precepto tampoco ha estado exenta de polémica. De la doctrina constitucional podría entenderse que la dicción del art. 22.3 de la $\mathrm{CE}$, que atribuye a la inscripción de las asociaciones en el registro el solo efecto de publicidad, hace deducir que la inscripción no es un requisito imprescindible para el ejercicio del derecho fundamental, por lo que esta solo se puede conceptuar como un derecho de la propia asociación, o, desde otra perspectiva, como una carga de cuyo cumplimiento se hace depender el disfrute de determinadas ventajas (en ese sentido, la STC 133/2006, de 27 de abril, FJ 11), por lo que quedaría fuera del ámbito de la competencia estatal sobre ordenación de los registros e instrumentos públicos.

Por lo que afecta a las "fundaciones», la doctrina constitucional sobre distribución de competencias entre el Estado y las CC. AA. aparece expuesta en la STC 341/2005, de 21 de diciembre ${ }^{16}$, en la que se resuelve el recurso interpuesto frente a la Ley de la Asamblea de Madrid 1/1998, de 2 de marzo, de Fundaciones. En ella, adoptando como punto de partida que en el texto constitucional el fenómeno fundacional no es considerado como materia competencial dotada de sustantividad propia, al no figurar en los listados de los arts. 148.1 y $149.1 \mathrm{CE}$, y el hecho de que las fundaciones se recogieron desde fecha temprana en varios estatutos de autonomía que proclamaron la competencia sobre las mismas de las respectivas CC. AA, entiende que de tal situación no puede extraerse la conclusión de que el Estado carezca de competencias en relación con el derecho de fundaciones proclamado en el art. $34 \mathrm{CE}$ (FJ 1). En este caso, junto con la necesidad de su desarrollo legislativo (art. 53.1 CE) y el título competencial que deriva del art. 149.1.1 CE relativo a la regulación de las condiciones básicas que garanticen la igualdad de todos los españoles en su ejercicio, el TC entiende que concurren otros títulos competenciales del Estado que le habilitan igualmente para disciplinar el régimen jurídico de las fundaciones en los aspectos civiles y procesales, entre los que cita expresamente el art. 149.1, apdos. 8 y 6, CE (ver FJ 4). Por ello, sostiene que será el legislador autonómico el habilitado para ejercer la amplia libertad de configuración que el texto constitucional le confiere cuando se trate de fundaciones que realicen su actividad principalmente en el territorio de la comunidad autónoma, mientras que lo será el estatal en los supuestos no cubiertos por las aludidas previsiones estatutarias; no obstante, al establecer el

15 Cuestión que el TC no ha abordado de forma directa en ninguna de las sentencias dictadas sobre esta materia. Una crítica a ello puede verse, entre otros, en De Pablo Contreras (1999) y Pérez Escalona (2006: 4).

16 RTC 341/2005. 
régimen jurídico de esos entes fundacionales, sostiene el TC que es evidente que la regulación autonómica habrá de respetar las competencias del Estado en las materias de legislación civil y procesal (art. 149.1, apdos. 8 y 6, CE, respectivamente), sin perjuicio de lo dispuesto en el art. 149.1.1 $\mathrm{CE}^{17}$. Por ello, respetando tales exigencias, el criterio de la territorialidad se erige como criterio determinante para sostener las competencias autonómicas en materia de fundaciones ${ }^{18}$.

Atendida la distribución de competencias sobre esta materia, la norma estatal vigente, la Ley 50/2002, de 26 de diciembre, determina en su art. 1 que constituye su objeto desarrollar el derecho de fundación, reconocido en el art. $34 \mathrm{CE}$, y establecer las normas de régimen jurídico de las fundaciones que corresponde dictar al Estado, así como regular las fundaciones de competencia estatal, enumerando en su disposición final primera los preceptos que son de aplicación general, al amparo de lo previsto en los arts. 149.1.1 y 8 de la CE.

De esta confluencia competencial entre el Estado y las CC. AA. resulta, al igual que ocurre con las asociaciones, una fragmentación registral, que en este caso se concreta en la existencia de un registro estatal único ${ }^{19}$, en el que se inscribirán las fundaciones de competencia estatal o que desarrollen sus funciones principalmente en el territorio de más de una comunidad autónoma, y una serie de registros autonómicos en los que se inscribirán las fundaciones de ámbito territorial, de lo que pueden surgir graves deficiencias en la ordenación legal de los registros de fundaciones, que han sido objeto de críticas doctrinales, entendiendo que las CC. AA. han procedido a configurar de facto sus respectivos registros de fundaciones como registros de seguridad jurídica ${ }^{20}$, todo ello aun cuanto, a priori, pudiera haberse considerado adecuado entender que no alcanza a los registros sobre personas jurídicas la reserva del art. 149.1.8 de la $\mathrm{CE}^{21}$.

De lo anteriormente expuesto podría concluirse que el TC no descarta que el criterio de la «materia» sea relevante a la hora de determinar el ámbito de aplicación de la competencia exclusiva sobre ordenación de los registros ex art. 149.1.8 CE, doctrina que viene reiterando en las sentencias en las que se habría de resolver sobre el alcance de esta competencia, tal como admite desde la Sentencia 71/1983. Por ello, tales registros serán exclusivamente los

17 En el mismo sentido, la STC 98/2013, de 23 de abril (FJ 2) (RTC 98/2013).

18 STC 31/2010, de 28 de junio (FJ 59) (RTC 31/2010).

19 El Real Decreto 1611/2007, de 7 de diciembre, aprueba el Reglamento del Registro de fundaciones de competencia estatal.

20 En este sentido puede verse el estudio de La Casa García (2014: 10 y ss.).

21 Así lo entendió en su día Marín López (1994: 164). 
civiles, esto es, los de derecho privado, descartando los registros mercantiles, que han de subsumirse en la competencia estatal sobre legislación mercantil. Conclusión que alcanza teniendo en cuenta la ubicación de esta excepción en el precepto en el que se determina la distribución de competencias sobre legislación civil entre el Estado y aquellas CC. AA. que la ostentan sobre la conservación, modificación y desarrollo de los derechos civiles forales o especiales allí donde existan.

Asimismo, precisa que tales registros son aquellos de carácter público y naturaleza jurídica, lo que parece cohonestarse con aquellos en los que la inscripción y publicación producen efectos jurídicos en las relaciones inter privatos (presunción de integridad y certeza, así como oponibilidad a terceros en las relaciones privadas), descartando aquellos otros cuya única finalidad es la de servir de mero instrumento de publicidad o control, que tendrían carácter puramente administrativo ${ }^{22}$. Y, asimismo, aquellos otros registros en los que la inscripción se configura con la única finalidad de ser un instrumento al servicio de la Administración a la hora de verificar el cumplimiento de los requisitos exigidos para obtener determinadas prestaciones de carácter estrictamente administrativo. Ello se observa con claridad a la hora de legitimar la adecuación a la CE de los registros de parejas de hecho o uniones estables, en los que, atendiendo exclusivamente a la materia, podría concluirse que esta entra de lleno dentro del ámbito de la legislación civil, por lo que su adecuación a la CE encuentra su amparo exclusivamente en los efectos con los que se configura $^{23}$. El problema en este caso es delimitar cuáles son efectos civiles de la inscripción y cuáles son los de carácter puramente administrativo, para lo

22 Como ya en su día señaló Gimeno y Gómez-Lafuente (1982: 1326), los registros que deben incluirse en el precepto deben reunir el siguiente requisito: ser civiles, ya que la reserva en exclusiva se predica de la legislación civil. No se incluye, por tanto, el Registro Mercantil en el art. 149.1.8, si bien al ser su regulación competencia exclusiva del Estado, según el número 6 del mismo, también queda fuera de la órbita autonómica su régimen jurídico. Además, deben ser públicos, ya que dicho adjetivo se predica al tiempo de los instrumentos y de los registros, y ser jurídicos.

23 En este sentido, la STC 93/2013, relativa a la Ley Foral Navarra 6/2000, de 3 de julio, para la igualdad jurídica de las parejas estables, refiere en su FJ 10: «La propia Ley Foral ofrece en su disposición adicional un instrumento destinado a probar la existencia de la pareja estable, al contemplar la facultad de creación de registros de parejas estables que faciliten, a través de la inscripción voluntaria, la prueba de su constitución, previsión que se cohonesta claramente con lo establecido en el art. 3» (RTC 93/2013). De la misma forma, la STC 81/2013 sobre la Ley de la Asamblea de Madrid 11/2001, de 19 de diciembre, de uniones de hecho, destaca que la inscripción en el registro lo es a los solos efectos de su acreditación (RTC 81/2013). 
que debe entenderse que la eficacia civil concierne, cualquiera que sea su configuración concreta, a la asignación de un determinado valor a lo publicado en las relaciones entre particulares afectados (Ruiz-Rico Ruiz y Casado Casado, 2004: 1176), resultando mucho más fácil de observar en aquellos casos en los que la normativa correspondiente se dicte por una de aquellas CC. AA. que no ostentan competencias en derecho civil foral o especial.

La vinculación a la materia como criterio determinante de atribución competencial en el ámbito de la excepción del art. 149.1.8 de la CE podría resultar también para los llamados registros de personas jurídicas -asociaciones, fundaciones y cooperativas-, materias todas ellas incluidas habitualmente en el ámbito del derecho privado, y respecto a las que gran parte de su régimen jurídico habría de incluirse en el ámbito de esta rama del derecho. Todo ello, por más que sea necesario reconocer que en esta, como en otras materias, es posible apreciar una evidente conexión entre diferentes ramas jurídicas. No obstante, parece consolidada la doctrina constitucional sobre su carácter de registro puramente administrativo.

Del análisis de las sentencias relativas a la distribución de competencias en materia de "asociaciones» podría entenderse, como vimos, que el TC adopta como prevalente el carácter de derecho fundamental que el art. $22 \mathrm{CE}$ otorga al derecho de asociación, así como la competencia estatal que deriva del art. 149.1.1 CE relativa a la regulación de las condiciones básicas que garanticen la igualdad de todos los españoles en el ejercicio de los derechos y cumplimiento de los deberes constitucionales. Siendo relevante el hecho de que el propio art. $22 \mathrm{CE}$ refiera que la inscripción lo es a los meros efectos de publicidad, entendida aquí como de mera publicación, puesto que los efectos que en su caso se pudieran atribuir a esta, tales como los relativos al nacimiento de su personalidad jurídica, debería establecerlos el Estado, según entiende, al amparo del citado art. 149.1.1 $\mathrm{CE}^{24}$. No obstante, es también doctrina consolidada del TC que el contenido material de la competencia autonómica en este caso no cabe circunscribirlo solo a los aspectos administrativos de las asociaciones, es decir, «sus relaciones de fomento, policía y sanción con los poderes públicos», sino extenderlo también al «régimen jurídico de las mismas tanto en su vertiente externa, es decir, la relativa a su participación en el tráfico jurídico - constitución, adquisición de personalidad jurídica, capacidad jurídica y de obrar, régimen de responsabilidad, extinción y disolución-, como en su vertiente interna —organización, funcionamiento interno y derechos

24 En este sentido, SSTC 135/2006, de 27 de abril (FJ 10) (RTC 135/2006), y 173/1998, de 23 de julio (FJ 14) (RTC 173/1998); más recientemente, la STC 144/2017, de 14 de diciembre (RTC 144/2017). 
y deberes de los asociados». Lo que no parece muy acorde con el régimen de distribución de competencias en materia de legislación civil, en la que se debe integrar parte del régimen jurídico de las asociaciones. En coherencia con tal doctrina constitucional, resulta comprensible que la naturaleza jurídica de los registros autonómicos de fundaciones no haya sido objeto de un pronunciamiento más específico por parte del TC, en la finalidad de determinar si objetivamente resulta posible calificar estos como registros meramente administrativos, desprovistos de efectos jurídicos sustantivos en las relaciones privadas, aun contemplados con independencia de la materia sobre la que inciden. Creo, desde esta perspectiva, que la solución adoptada por el TC resulta insuficiente.

Una conclusión similar puede alcanzarse en relación con las «fundaciones», respecto a las que el propio TC ha venido a apreciar en sus resoluciones alguna extralimitación competencial, con fundamento en el art. 149.1.8 CE en legislación civil. Siguiendo el hilo argumental antecedente, desde el estricto punto de vista de la competencia sobre ordenación de los registros e instrumentos públicos, lo relevante en este caso no es tanto la materia a la que afecta, ni la territorialidad en la que las fundaciones desarrollen su actividad, sino la naturaleza y alcance de los efectos jurídicos sustantivos que derivan de la inscripción y su incidencia en el ámbito del derecho privado, sobre lo que no existe un pronunciamiento claro, generando una especial confusión en la aplicación de la propia doctrina del TC a supuestos diferentes, expuesta en las sentencias en las que esta se manifiesta, de las que la STC 7/2019 es un claro ejemplo.

Estas deficiencias, que ahora se centran en el alcance de la competencia exclusiva sobre ordenación de los registros e instrumentos públicos, pero que pueden extenderse a otras cuestiones en relación con los conflictos constitucionales sobre distribución de competencias, determinan la complejidad que genera en su aplicación práctica el sistema establecido en la $\mathrm{CE}$, por lo que afecta a la legislación civil ex art. 149.1.8 CE. Ello se observa no solo en lo que atañe a la delimitación del alcance de aquellas que pueden asumir las CC. AA. que tienen derecho foral o especial — las menos-, sino también por la multiplicidad de normas dictadas por el legislador autonómico atendiendo a su naturaleza instrumental respecto a materias competenciales asumidas estatutariamente. A todo ello se une, además, el carácter dispositivo de la justicia constitucional, que propicia actuaciones aleatorias en cuanto a la formulación del oportuno recurso ante el TC, en tanto que, pudiendo afectar la tacha de inconstitucionalidad a normas con idéntico contenido dictadas por varias CC. AA., solo se formula el recurso frente a algunas de ellas, lo que puede propiciar, al menos en un inicial punto de vista, opiniones relativas a la existencia de una cierta instrumentalización del recurso a fines diferentes 
a los que deben presidir la justicia constitucional ${ }^{25}$. De la misma forma, este carácter dispositivo de la justicia constitucional puede propiciar la dificultad para comprender la doctrina constitucional en algunos casos, en tanto que esta se encuentra condicionada por el contenido del propio recurso interpuesto y el alcance con el que este se formule, lo que genera cierta inseguridad al comparar la doctrina constitucional sobre una misma materia contenida en diferentes resoluciones, al poderse apreciar soluciones en cierta forma contradictorias. Quizá estos sean algunos de los argumentos que propician el voto particular contenido en la STC 7/2019, que analizaré con posterioridad.

\section{DISPOSICIÓN MORTIS CAUSA DEL PATRIMONIO DIGITAL. EL REGISTRO ELECTRÓNICO DE VOLUNTADES DIGITALES Y LA COMPETENCIA ESTATAL SOBRE ORDENACIÓN DE LOS REGISTROS E INSTRUMENTOS PÚBLICOS}

\section{LAS DISPOSICIONES SOBRE EL CONTENIDO DIGITAL PARA EL CASO DE FALLECIMIENTO. SU ORDENACIÓN JURÍDICA}

La Ley 10/2017, de 17 de febrero, de las Voluntades Digitales y de modificación de los Libros Segundo y Cuarto del CC de Cat., pionera en nuestro país en la ordenación normativa de algunos aspectos relativos a lo que se ha venido a denominar «huella digital» de la persona tras su fallecimiento, permite que, en el ejercicio de la autonomía de la voluntad, las personas con vecindad civil catalana puedan establecer determinadas previsiones en esta materia ${ }^{26}$.

A tenor de lo dispuesto en su preámbulo, la ley adopta como punto de partida que las personas utilizan cada vez con más frecuencia los entornos digitales para desarrollar las actividades de su vida personal y profesional, actividades que generan una diversidad de archivos que, una vez muertas, también forman su legado. Del mismo modo, entiende el legislador catalán

25 Puede verse una interesante crítica sobre ello en García Rubio (2017: 16).

26

Como antecedente en derecho extranjero suele citarse la Ley francesa 2016-1321, de 7 de octubre de 2016, para una República Digital. También en derecho extranjero es habitual aludir a las medidas adoptadas en Estados Unidos con la publicación de determinadas leyes federales, en las que, entre otras cosas, se aborda la situación de los administradores de los bienes de una persona fallecida en el ámbito digital, entre las que debe destacarse la Revised Uniform Fiduciary Acces to Digital Assets Act (RUFADAA), publicada en 2015. Un análisis de estas medidas puede verse en Santos Morón (2018: 15), al ser imposible su tratamiento en este trabajo, dado su reducido ámbito. También puede verse un estudio de tales normas en Ginebra Molins (2018: RB-3.6 y RB-3.7). 
que después de la muerte pueden quedar unos derechos y unas obligaciones de naturaleza jurídica diversa sobre los diferentes archivos que haya generado la actividad de los prestadores de servicios, respecto a los cuales debe decidirse qué hacer. Por ello, para dar respuesta a estas cuestiones, se consideraba necesario impulsar unas disposiciones que determinasen la forma de administrar la presencia de las personas en los entornos digitales a su muerte ${ }^{27}$.

En concreto, los párrafos 1 y 2 de su art. 6, por medio del cual se introduce el art. 411-10 al Libro cuarto del CC de Cat., determinan el contenido y alcance de las llamadas «voluntades digitales en caso de muerte», entendiendo por tales las disposiciones establecidas por una persona para que, después de su muerte, el heredero o el albacea universal, en su caso, o la persona designada para ejecutarlas, actúe ante los prestadores de servicios digitales con quienes el causante tenga cuentas activas.

Literalmente puede leerse en el art. 6.2:

El causante, en las voluntades digitales en caso de muerte, puede disponer el contenido y el alcance concreto del encargo que debe ejecutarse, incluyendo que la persona designada lleve a cabo alguna o algunas de las siguientes actuaciones: a) Comunicar a los prestadores de servicios digitales su defunción. b) Solicitar a los prestadores de servicios digitales que se cancelen sus cuentas activas. c) Solicitar a los prestadores de servicios digitales que ejecuten las cláusulas contractuales o que se activen las políticas establecidas para los casos de defunción de los titulares de cuentas activas $y$, si procede, que le entreguen una copia de los archivos digitales que estén en sus servidores.

De su lectura, podría señalarse que lo dispuesto en esta norma es lo suficientemente amplio como para permitir al otorgante de las voluntades digitales manifestar su voluntad sobre el contenido y alcance de la actuación de la persona designada, previendo la ley un contenido específico, en el que se incluyen algunas de las actividades que podrían encomendarse ${ }^{28}$, pero, a su vez, lo sufi-

27 Por medio de esta norma se modifica también el libro segundo del CC de Cataluña, disponiendo la posibilidad de que se pueda otorgar un poder en previsión de pérdida sobrevenida de capacidad, en el que se pueda fijar quién se encargará de ejecutar las voluntades digitales y establecer el alcance de la gestión dentro del poder. Regulando, asimismo, la facultad de vigilancia de los progenitores y tutores de los menores de edad para que la presencia de estos en los entornos digitales sea apropiada y no les genere riesgos, del mismo modo que se establece que los progenitores y tutores puedan promover las medidas adecuadas y oportunas y solicitar la asistencia de los poderes públicos.

Como veremos más adelante, la dicción del precepto es susceptible de generar variadas interpretaciones. 
cientemente limitado, en tanto que las voluntades digitales se prevén exclusivamente en relación con la actuación de los designados frente a los prestadores de servicios digitales, y también con un limitado alcance, en cuanto que el ámbito de actuación del designado puede verse restringido por el contenido de los contratos concluidos con el prestador de servicios digitales ${ }^{29}$.

Ciertamente, tal como dispone el preámbulo de dicha ley, los derechos y obligaciones de naturaleza jurídicas sobre los diferentes archivos que haya generado el causante con los prestadores de servicios digitales pueden tener naturaleza muy diversa, por lo que la norma no prejuzga sobre este, que puede tener carácter patrimonial o meramente personal. Si el contenido generado por el causante tiene carácter patrimonial, es evidente que con esta misma naturaleza se ha de integrar en su herencia ${ }^{30}$, pudiendo haber dispuesto de él el fallecido conforme a las normas que regulan la sucesión voluntaria y rigiéndose su destino, a falta de disposición expresa, por las normas que regulan la sucesión intestada ${ }^{31}$. Junto con ello, la dinámica de la actuación cotidiana en la Red permite generar otro tipo de contenidos, desprovistos de valor económico, cuya permanencia en la Red puede perdurar tras el fallecimiento. Lo que ocurre es que, en muchas ocasiones, la dinámica a través de la que se desarrollan las relaciones en Internet dificulta el conocimiento de la propia existencia del contenido digital generado en vida del causante o de sus claves de acceso $^{32}$, por lo que, siendo cierto que en la actualidad ya existen empre-

29 El limitado alcance de la norma autonómica ha sido igualmente destacado por Santos Morón (2018: 435), resaltando que podría entenderse de su dicción literal que la posible voluntad del causante, de existir, quedaría supeditada a lo que establecieran las condiciones generales de los contratos suscritos con los prestadores de servicios.

30 En este sentido se ha dicho que el patrimonio digital sería, en síntesis, todo aquello que su titular envía, recibe, almacena, comparte, gestiona o contrata vía Internet y que puede valorarse desde un punto de vista económico (García Herrera, 2018: 2).

31 Lo que parece admitirse con carácter general por la doctrina. En este sentido, entre otros, podemos citar a González Granados (2015), quien señala que la equiparación entre relaciones jurídicas analógicas o digitales es absoluta cuando se trata de relaciones de contenido patrimonial. Autor a quien también cita en el mismo sentido Solé Resina (2018: 421). En la misma línea, García Herrera (2018: 2). También Ginebra Molins (2018: RB-3.3) entiende que, aunque efectivamente no cabe distinguir entre herencia digital y herencia analógica, los activos digitales presentan cierta especificidad que debe tenerse en cuenta y que está en función del tipo de activo digital de que se trate.

32 La dificultad de que los sucesores puedan conocer del contenido digital que generó el causante en vida es un dato resaltado frecuentemente por la doctrina que ha estudiado el tema, puesto que es posible que este no hubiera ni tan siquiera comunicado a sus sucesores su existencia, o que estos no conozcan las posibles claves de acceso. En este 
sas que ofrecen servicios muy diversos dirigidos a su administración, ello no obsta a la conveniencia de adoptar determinadas normas específicas dirigidas a solventar estas cuestiones.

Quienes han estudiado esta materia coinciden en señalar las especificidades que derivan para la ordenación mortis causa de estos bienes de naturaleza o carácter digital, que, pese a las dificultades existentes para su definición, alcanzarían a cualquier información o archivo de carácter digital que dispusiera el fallecido almacenado localmente u online (Santos Morón, 2018: 416). Dicha especialidad se presenta en mayor grado cuando se trata de bienes que pueden englobarse dentro de los que tendrían naturaleza extrapatrimonial, que difícilmente podrían entenderse incluidos dentro de la herencia, por más que esta comprenda todos los bienes, derechos y acciones que no se extinguen a la muerte del causante (art. 659 CC) ${ }^{33}$.

La Ley 10/2017 de Cataluña, en la regulación de esta materia, prevé que las voluntades digitales puedan expresarse en testamento, codicilo o memoria testamentaria, a tenor de lo dispuesto en su art. 6. Por ello, su art. 7 modifica el art. 421-2 del CC de Cat., en el que se determina el contenido del testamento, de forma que, conforme a su párrafo 2 :

El testamento, además de lo establecido por el apartado 1, puede contener las voluntades digitales del causante y la designación de una persona encargada de su ejecución. En defecto de designación, el heredero, el albacea o el administrador de la herencia pueden ejecutar las voluntades digitales o encargar su ejecución a otra persona.

En su redacción inicial, el art. 6 de la norma preveía la posibilidad de que tales voluntades digitales, si la persona no había otorgado disposición de última voluntad, pudieran contenerse en un documento de voluntades digitales

sentido, entre otros, puede citarse a García Herrera (2018: 3) y Solé Resina (2018: 422). Por esta razón, Ginebra Molins (2018: RB-3.11) entiende que, desde un punto de vista práctico, sería conveniente que al manifestar su voluntad el causante (en cualquier forma que se admita) debería acompañar una especie de «inventario digital» a fin de identificar todos los servicios de correo electrónico, plataformas de almacenamiento, blogs, páginas web, redes sociales...

33 Sobre esta cuestión, señala Cámara Lapuente (2019) que para delimitar el posible contenido digital de la herencia es preciso distinguir entre la tutela post mortem de los aspectos personales o morales de la personalidad pretérita que no integran la herencia y unos derechos patrimoniales de explotación de algunos derechos de la personalidad que sí podrían integrarla, junto con los derechos de explotación de la propiedad intelectual, transmisibles mortis causa durante los setenta años posteriores al fallecimiento. 
que habría de inscribirse en el registro creado al efecto, y cuya falta de adecuación a la CE se resuelve en la STC 7/2019, que analizaré con posterioridad.

Finalmente, la norma prevé la posibilidad de modificación de dichas voluntades en cualquier momento, regulando el alcance del ámbito de actuación del heredero o albacea universal en este punto para los casos en los que el causante no haya expresado su voluntad. Conforme a dicha norma, estos podrán ejecutar las actuaciones previstas en las letras a, b y c del art. 410-2 del CC de Cat., de acuerdo con los contratos que el causante haya suscrito con los prestadores de servicios digitales o de acuerdo con las políticas que estos prestadores tengan en vigor.

Es evidente el acierto del legislador catalán en esta ordenación pionera de las voluntades digitales para el caso de fallecimiento, no obstante el limitado ámbito al que se extiende, condicionado, como dije, a las disposiciones que puedan contenerse en los contratos que hubiere concluido el fallecido con los prestadores de servicios digitales ${ }^{34}$.

Junto con ello, el marco normativo debe completarse con lo dispuesto en la reciente Ley Orgánica 3/2018, de 5 de diciembre, de Protección de Datos, en la medida en que determinado contenido digital, en cuanto permita la identificación de su titular, puede considerarse datos personales. Pues bien, el art. 2 de esta norma excluye de su ámbito de aplicación el tratamiento de los datos de las personas fallecidas. No obstante, su art. 3 permite que las personas vinculadas al fallecido por razones familiares o de hecho, así como sus herederos, puedan solicitar el acceso a los datos personales de aquellos, su rectificación o supresión, salvo que la persona fallecida lo hubiere prohibido expresamente o así lo establezca la ley; prohibición que no afectará a los datos de carácter patrimonial del causante. La norma prevé que las personas o instituciones a las que el fallecido hubiese designado expresamente para ello puedan también solicitar, con arreglo a las instrucciones recibidas, el acceso a los datos personales de este, y, en su caso, su rectificación o supresión. Para ello se remite a un real decreto en el que se establecerán los requisitos y condiciones para acreditar la validez de estos mandatos e instrucciones, y, en su caso, su registro. Se implantan, finalmente, medidas para el caso de fallecimiento de menores o personas con discapacidad.

34 Coincido con Santos Morón (2018: 435) en que la ley catalana deja en manos de las empresas de Internet la decisión acerca del destino de los bienes digitales del difunto, como en realidad ya se viene haciendo en la práctica. Conclusión que alcanza de la relevancia que atribuye la norma a los acuerdos alcanzados por el causante en vida, y a las políticas que estos prestadores tengan en vigor. 
La ley da un paso más en el reconocimiento de los problemas que puede generar la huella digital al fallecimiento de la persona, y consciente de que no todo el contenido digital generado en vida puede considerarse datos personales, regula en su art. 96, y bajo la rúbrica general «Derecho al testamento digital», el acceso a los contenidos gestionados por los prestadores de servicios de la sociedad de la información, a las personas vinculadas al causante por razones familiares o de hecho, así como al albacea testamentario o persona que expresamente hubiere designado el fallecido ${ }^{35}$. Pudiendo los primeros acceder a los contenidos gestionados por los prestadores de servicios a fin de impartir las instrucciones que estimen oportunas sobre su utilización, destino o supresión; no pudiendo acceder a su contenido ni solicitar su modificación o eliminación si la persona fallecida lo hubiese prohibido expresamente o así lo establezca una ley. Dicha prohibición no afectará al derecho de los herederos a acceder a los contenidos que pudiesen formar parte del caudal relicto. Mientras que, en cuanto al alcance de la actuación del albacea o de las personas designadas expresamente, se limita al cumplimiento de las instrucciones del causante. Por último, la ley también regula la actuación de los representantes legales de los fallecidos menores de edad y de aquellos que hubieren sido designados para realizar medidas de apoyo en el caso de personas con discapacidad, si tales facultades se entendieran comprendidas en las medidas de apoyo prestadas por el designado.

En relación con el alcance de la actuación de quienes ostenten legitimación, la ley determina también que estos podrán decidir acerca del mantenimiento o eliminación de los perfiles personales en redes sociales o servicios equivalentes, a menos que el fallecido hubiera decidido acerca de esta circunstancia, en cuyo caso se estará a sus instrucciones. Disponiendo que el responsable del servicio al que se le comunique, con arreglo al párrafo anterior, la solicitud de eliminación del perfil, deberá proceder sin dilación a la misma.

Finalmente, la norma remite a un real decreto que deberá dictarse en el que «se establecerán los requisitos y condiciones para acreditar la validez y vigencia de los mandatos e instrucciones y, en su caso, el registro de los mismos, que podrá coincidir con el previsto en el artículo 3 de esta ley orgánica». Todo ello, con respeto a lo que hubieren podido establecer las CC. AA. con derecho civil, foral o especial en el ámbito de sus competencias y para las personas a las que resulte de aplicación.

35 Una crítica a esta norma puede verse en Cámara Lapuente (2019), al señalar: «Debe descartarse, para delimitar qué se puede heredar, una noción general y omnicomprensiva de "contenidos digitales", como la que presupone el artículo 96 LOPD, sin ofrecer ninguna definición». 
No procede en estas páginas un análisis preciso de estas normas, que ya desde su inclusión en el Proyecto de Ley Orgánica de Protección de Datos fueron objeto de algún comentario en el que se pone en duda que puedan solventar todos los problemas ligados a la transmisión mortis causa de los bienes digitales $^{36}$. No obstante, creo que resultan destacables algunos aspectos que se reflejan de la literalidad de las normas contenidas en la Ley Orgánica 3/2018.

Así, en primer lugar, el encabezado de su art. 96, en el que las reglas contenidas se enuncian bajo la rúbrica general: «Testamento digital». Atendiendo al contenido de la norma, parece evidente que con ella se está refiriendo, junto con reglas específicas a falta de voluntad expresa del causante, a las disposiciones mortis causa de los bienes digitales del fallecido, fruto de una declaración de voluntad previa a su fallecimiento, pero no parece que el legislador pretenda circunscribir la regulación de estas últimas a las que se efectúen por medio de testamento ${ }^{37}$. Una lectura atenta del precepto permite observar que en ningún momento el legislador contempla que tales estipulaciones deban incluirse en el testamento como negocio jurídico mortis causa. La única referencia al testamento se contiene en el art. 96. 1 b), cuando establece las facultades que se atribuyen al «albacea testamentario» (en concordancia con el art. 892 del CC). Por ello, atendiendo al contenido de la norma, quizá hubiera sido más correcto prescindir de esta referencia al testamento en el enunciado del precepto, aun cuando ciertamente el testamento es el instrumento jurídico más adecuado para ordenar las decisiones relativas a los bienes digitales de la persona al momento de su fallecimiento, por más que se hayan querido resaltar algunas de las especificidades que acompañarían a las estipulaciones testamentarias sobre esta materia (García Herrera, 2018: 4; Prados Ramos, 2014). Tampoco se observa ninguna referencia al testamento en el art. 3 de la norma, en cuanto a la necesidad de que la voluntad de la persona respecto a las acciones a realizar relativas a sus datos personales a su fallecimiento deba expresarse en testamento. Ello no obsta que el legislador pueda regular la posibilidad de que unas u otras disposiciones se ordenen fuera del testamento, tal como reguló el legislador catalán en la Ley 10/2017. Quizá el precepto, pese a lo inadecuado de su rúbrica, abra una vía para tal solución ${ }^{38}$.

36 Así, puede verse en Santos Morón (2018: 438).

37 No parece que el legislador contemple aquí ninguna otra acepción de dicha expresión, con la que alguna vez se ha identificado el testamento que, en su caso, se pudiera hacer usando exclusivamente medios digitales. Sobre esta distinción, puede verse García Herrera (2018: 4).

38 No obstante, he de coincidir con Cámara Lapuente (2019) en que el testamento notarial es el instrumento idóneo para disponer del patrimonio digital: a) por la flexibilidad de su contenido, que puede abarcar disposiciones patrimoniales y extrapatrimoniales; $b$ ) 
En segundo lugar, de esta primera lectura resulta destacable el hecho de que ambas normas excluyen la posibilidad de que se establezcan restricciones que pudieran afectar a los datos o bienes digitales que pudieran tener naturaleza patrimonial.

Por último, destaca también el hecho de que tanto el art. 3 como el 96 de la Ley Orgánica de Protección de Datos dispongan que mediante real decreto se establecerán las condiciones para acreditar su validez y vigencia, $y$, en su caso, su registro. La ley abre la posibilidad de que el registro sea único para tales disposiciones. Es evidente que esta referencia ofrece un dato más para entender que el legislador está pensando en la posibilidad de que las declaraciones de voluntad sobre estas materias puedan formalizarse al margen del testamento, puesto que, si estas se ordenan en testamento, es evidente que gozan de las garantías relativas a la vigencia y validez que están ya establecidas para este negocio jurídico ${ }^{39}$.

Habrá que esperar a la aprobación de la norma de desarrollo, valorando el avance de forma positiva desde este momento. Aun con sus limitaciones, los preceptos transcritos ponen de manifiesto una preocupación del legislador por la ordenación jurídica de una materia conforme lo exigen las nuevas condiciones sociales.

\section{EL REGISTRO ELECTRÓNICO DE VOLUNTADES DIGITALES DE CATALUÑA Y LA COMPETENCIA ESTATAL SOBRE ORDENACIÓN DE LOS REGISTROS E INSTRUMENTOS PÚBLICOS. LA STC 7/2019, DE 17 DE ENERO}

El recurso resuelto por el TC en la Sentencia 7/2019, de 17 de enero ${ }^{40}$, versaba sobre determinados artículos de la Ley 10/2017, de 27 de junio, de voluntades digitales de Cataluña y de modificación de los Libros Segundo y Cuarto del CC de Cataluña, examinada con anterioridad. Los preceptos que

por la garantía de la identidad y capacidad del otorgante que comporta: si la identidad puede resolverse con la firma electrónica (y el control material, formal y de legalidad del documento también pueden hacerse a distancia), la fe de capacidad requiere verificación personal del notario, que así comprobará la plena capacidad y libertad del compareciente, y c) extinguida la personalidad, el testamento es el único medio legal para nombrar auténtico albacea o heredero, con plena legitimación frente a terceros.

39 Similar conclusión alcanza Solé Resina (2018: 427), al señalar, con referencia al proyecto de ley orgánica, que este no desvelaba cuál habría de ser la forma en la que se dispongan las voluntades digitales, aunque de la referencia a la posibilidad de inscripción se deduce la idea de que en el reglamento se regulará un instrumento especial al efecto, diferenciado de los documentos válidos para las disposiciones de última voluntad.

RTC 7/2019. 
fueron objeto de impugnación ante el TC fueron algunos de los contenidos en su capítulo II, relativos a las voluntades digitales para después de la muerte, en concreto, sus arts. 6, 8, 10 y 11 y su disposición final primera.

Tras la modificación dada, y conforme al art. 411.10.3 b) del libro cuarto del CC de Cat., las voluntades digitales podrían ordenarse por el causante de vecindad civil catalana, si este no ha otorgado disposiciones de última voluntad (testamento, codicilo o memoria testamentaria), por medio de un documento que debía inscribirse en el registro electrónico de voluntades digitales. De igual forma, tras la redacción practicada por el art. 8 de la ley, el apartado 1 del art. 421.24 del libro cuarto del CC Cat., al referirse a la designación de la persona encargada de ejecutar las voluntades digitales, determinaba que tal designación podría hacerse por medio de un documento que deberá especificar el alcance concreto de su actuación y que debería inscribirse en el registro de voluntades digitales. Junto con ello, su art. 10 añadía la disposición adicional tercera del libro cuarto del CC de Cat., en donde se aborda la regulación del registro electrónico de voluntades digitales, en el que habrían de inscribirse estas. Dicho registro estaría adscrito al departamento competente en materia de derecho civil; su acceso estaría reservado al titular otorgante, y, una vez muerto aquel, a las personas que menciona y cuando acrediten mediante certificado de actos de última voluntad que el causante no ha otorgado disposiciones de última voluntad; dicho acceso se restringe a las personas que acrediten interés legítimo, quienes podrán solicitar un certificado relativo a la existencia o no de un documento de voluntades digitales, y si el causante no hubiere dispuesto otra cosa, el certificado podría extenderse a la identificación de las personas designadas para la ejecución de las voluntades digitales; sin perjuicio de ello, los certificados relativos al contenido de las voluntades digitales, una vez muerto el titular, solo podrían solicitarlos y solo podrían entregarse a las personas designadas para su ejecución, disponiéndose finalmente que el registro podrá de oficio comunicar la existencia de voluntades digitales inscritas a las personas designadas, si le consta la muerte del otorgante ${ }^{41}$. Para la organización, el funcionamiento y el acceso al registro electrónico de

41 Literalmente disponía esta norma, bajo la rúbrica general «Registro electrónico de voluntades digitales»:

«1. Se crea el Registro electrónico de voluntades digitales, adscrito al departamento competente en materia de derecho civil por medio del centro directivo que tenga atribuida la competencia.

2. En el Registro electrónico de voluntades digitales se inscriben los documentos de voluntades digitales.

3. El acceso al Registro electrónico de voluntades digitales está reservado al titular otorgante y, una vez muerto el titular, a las personas que se mencionan en los aparta- 
voluntades digitales, el art. 11 de la ley se remitía al desarrollo reglamentario de la norma, conforme a lo dispuesto en la disposición final quinta del libro cuarto del CC de Cat. que se añadía; en concreto, a una orden del consejero correspondiente en materia de derecho civil, tal como establecía la disposición final primera de la ley, también impugnada.

Pues bien, el recurso interpuesto ante el TC tenía un fundamento exclusivamente competencial (sic) ${ }^{42}$, argumentado en la consideración de que el registro creado, pese a lo que señalaba el preámbulo de la propia ley, no era un registro administrativo, sino un registro jurídico de derecho privado, por lo que se invadía la competencia estatal de carácter exclusivo sobre esta materia, al amparo del art. 149.1.8 CE. Dicha naturaleza jurídica la fundamentaba el abogado del Estado en el hecho de que en este registro se inscriben únicamente documentos de voluntades digitales, que serían el instrumento por el que las personas pueden disponer mortis causa de sus archivos digitales frente a los prestadores de servicios de la sociedad de la información, designando a las personas encargadas de ejecutarlas en defecto de testamento, codicilo o memoria testamentaria. Que, por tanto, dicho registro no era un simple registro administrativo, sino que desplegaba sus efectos jurídicos sustantivos sobre las relaciones privadas, puesto que en él se dejaba constancia de la última voluntad en un aspecto concreto de la sucesión, como era el destino que otorgan las personas a sus archivos digitales generados en vida.

Con estos antecedentes, la STC 7/2019, de 19 de enero, previamente a determinar la naturaleza del registro creado en la Ley 10/2017, de 27 de

dos siguientes, siempre y cuando acrediten, mediante el certificado de actos de última voluntad, que el causante no ha otorgado disposiciones de última voluntad.

4. Una vez muerto el titular, las personas que acrediten un interés legítimo pueden solicitar un certificado relativo a la existencia o no de un documento de voluntades digitales inscrito en el Registro electrónico de voluntades digitales. A solicitud de la persona interesada, si el causante no dispuso otra cosa, el certificado puede extenderse a la identificación de las personas designadas para la ejecución de las voluntades digitales.

5. Sin perjuicio de lo dispuesto por el apartado 4, los certificados relativos al contenido de las voluntades digitales inscritas en el Registro electrónico de voluntades digitales, una vez muerto el titular, únicamente pueden solicitarlos las personas designadas para la ejecución de las voluntades digitales y solo pueden entregarse a estas personas. 6. El Registro electrónico de voluntades digitales, si le consta la muerte de un otorgante, puede comunicar de oficio la existencia de voluntades digitales inscritas a las personas designadas para su ejecución, de acuerdo con lo que se establezca por reglamento».

42 Lo que reconoce expresamente el TC en su FJ 1. 
junio, del Parlamento de Cataluña, analiza nuevamente el alcance de la competencia estatal sobre ordenación de los registros e instrumentos públicos ex art. 149.1.8 CE, atendidas las alegaciones que formulan tanto el abogado del Estado como los representantes legales del Parlamento y el Gobierno de la Generalitat.

Tanto en las citadas alegaciones como en los razonamientos del TC, subyace la clásica distinción entre los llamados registros jurídicos o de configuración jurídica y los registros meramente administrativos. Los primeros, con presunción de integridad y certeza, así como de la oportuna oponibilidad, llamados a proyectar sus efectos jurídicos sustantivos sobre las relaciones privadas; mientras que los segundos, con efectos de mera publicación, distinguiendo así entre lo que sería la publicación como efecto o como mera noticia, acuñada por la doctrina al efecto de diferenciar entre unos y otros. Así, por más que se haya tratado de señalar que dicha distinción no deja de adolecer de cierta imprecisión, dada la tipología de los diferentes registros de uno u otro tipo ${ }^{43}$, la distinción sigue vigente, siendo la publicidad efecto privilegio de los registros jurídicos, como ha venido señalando desde antiguo la doctrina ${ }^{44}$.

En la necesidad de distinguir entre una clase y otra de registro a efectos de subsumir el creado en el ámbito de los registros administrativos, tanto el letrado del Parlamento de Cataluña como el de la Generalitat insisten en el carácter de archivo de documentos que ha de otorgarse a aquellos registros de naturaleza administrativa ${ }^{45}$.

En sentido contrario, el dictamen emitido por el Consejo de Estado, previo a la interposición del recurso de inconstitucionalidad ${ }^{46}$, sostiene claramente que para este órgano consultivo dicho registro no se configura como un instrumento puramente administrativo al servicio de un mejor desarrollo de sus propias competencias por parte de la comunidad autónoma, sino como un instrumento de derecho privado en el que queda constancia de la última voluntad de la persona en relación con un aspecto concreto de la sucesión, esto es, del destino de los bienes digitales del causante tras su fallecimiento.

En la doctrina, también alguna autora ha defendido la justificación de la naturaleza meramente administrativa de este registro (Solé Resina, 2018: 437

43 Por todos, Leyva de Leyva (1989: 270).

44 Entre otros autores, podemos citar a Chico Ortiz (1982: 1177).

45 Así, entienden que la comunidad autónoma de Cataluña, en el ejercicio de sus competencias, en este caso en el ámbito del derecho civil y de organización de la Administración de la Generalitat, puede crear registros para facilitar el conocimiento de las voluntades digitales, adecuándose su actuación al régimen constitucional vigente.

46 Núm. 725/2017, de 21 de septiembre de 2017. 
y ss.). En este sentido, como argumento a favor del carácter administrativo del registro alude al hecho de que en las voluntades digitales reguladas no se contiene la ordenación del «legado» digital en el sentido del conjunto de materiales o archivos que pudieran tener valor patrimonial y que evidentemente se integran en el caudal hereditario, comprendiendo exclusivamente las actividades que menciona. Ciertamente hay que admitir la razón de que la norma no prevé expresamente ninguna disposición relativa al destino de los bienes digitales que pudieran tener carácter patrimonial, que, obviamente, deben seguir el de los bienes de esta naturaleza al fallecimiento del causante. Sin embargo, la redacción del precepto no es tan clara en cuanto al contenido de las voluntades digitales. La literalidad de la norma podría alcanzar a la interpretación que se mantiene para justificar la naturaleza administrativa del registro, quedando limitada la actuación del designado a cualquiera de los actos que enumera, esto es, a comunicar a los prestadores de servicios su defunción y que se cancelen las cuentas activas; a que ejecuten las cláusulas contractuales o que se activen las políticas establecidas para los casos de defunción, y a que, en su caso, libren una copia de los archivos que estén en sus servidores, pero entiendo que en su redacción no queda tan claro que no pueda extenderse a otras actuaciones ${ }^{47}$. Por lo pronto, resulta de la ley que la actuación del designado puede alcanzar a conocer el contenido de los archivos digitales que, obviamente, puede tener naturaleza patrimonial. En efecto, tal como se expresa en ella, el causante puede disponer el contenido y el alcance concreto del encargo, que incluye cualquiera de las actuaciones que señala el art. 411-10.2 del libro cuarto del CC de Cat., pero, junto con ello, el causante puede también disponer que el designado pueda acceder al contenido de sus cuentas y archivos digitales, conclusión que se alcanza de una interpretación $a$ sensu contrario del apartado 6 de ese mismo artículo, puesto que, conforme a esta norma, si no se contempla tal posibilidad en el documento de voluntades digitales, el designado solo podrá acceder al contenido de los archivos digitales mediante autorización judicial. Además, no contempla la ley ninguna previsión respecto al acceso de los sucesores del causante al hipotético contenido patrimonial de estos archivos, tal como prevé la Ley Orgánica de Protección de Datos, por lo que el hecho de que la ley catalana permita acceder al contenido de los archivos digitales del causante, cualquiera que sea su naturaleza, puede tener implicaciones en el derecho de sucesiones, particularmente en aquellos casos en los que los designados en las voluntades digitales sean ajenos

47 Ginebra Molins (2018: RB 3.8) entiende que la ley prevé a título meramente ejemplificativo algunas de las facultades que pueden integrarse en el contenido de las voluntades digitales. 
a la herencia, siendo una de las particularidades que acompañan a los bienes de esta naturaleza la dificultad que puede aparecer en relación con el conocimiento de su existencia y alcance. No quedando tan claro del argumento expuesto para fundamentar el carácter administrativo del registro que la inscripción de las voluntades digitales no pueda producir efectos jurídicos en los derechos de naturaleza patrimonial del causante que, en tal condición, se transmiten mortis causa a su fallecimiento, aun cuando la ley no contenga de forma expresa previsión alguna relativa a su destino.

Por otro lado, y como vimos al analizar la doctrina del TC en relación con el alcance de la competencia relativa a la ordenación de los registros e instrumentos públicos, para el TC no es tan solo la materia lo que determina la naturaleza administrativa del registro, sino los efectos jurídicos sustantivos que esta está llamada a producir, efectos que, por lo que afecta a este registro, se concretan en la sentencia.

Esto es precisamente lo que intenta resaltar el letrado de la Generalitat de Cataluña, para quien se trataría de un registro administrativo unido a la competencia que ostenta esta comunidad autónoma en derecho civil (sic), que, en lo que ahora interesa, se habría de incluir dentro del derecho de sucesiones, competencia material a la que habría de vincular la constitución y regulación de este registro, como vimos con anterioridad.

Pues bien, en esta resolución, el TC, rechazando las alegaciones propuestas para fundamentar el carácter meramente administrativo del registro, reitera la doctrina contenida en sentencias precedentes y vuelve a incidir en la argumentación de que los registros que han de subsumirse en el ámbito del art. 149.1.8 CE son aquellos que producen efectos jurídicos sustantivos en el ámbito del derecho civil.

La sentencia establece con claridad que lo discutido en este caso no alcanza a las competencias que ostenta la comunidad autónoma en materia de derecho civil (art. 129 EAC y STC 31/2010, de 28 de junio, FJ $76^{48}$ ), por lo que ha de admitirse que esta comunidad puede regular las disposiciones jurídicas mortis causa en el derecho civil catalán (testamento, codicilo y memoria testamentaria), como efectivamente hace en la Ley 10/2017; en este caso, el problema surge de la regulación de la ordenación de las voluntades digitales en un documento que surte efectos desde la inscripción en el registro.

El TC entiende que la ley establece con claridad que el documento en el que se plasman las voluntades digitales ha de inscribirse en el registro para que despliegue eficacia, destacando que es precisamente dicha inscripción la

48 RTC 31/2010. 
que determina que dicho documento despliegue efectos jurídicos sustantivos en el derecho sucesorio.

En sentido contrario, la magistrada Roca i Trias, en el voto particular emitido, entiende que del texto del art. 411-10-3 b) no se deduce que la sola inscripción del documento de voluntades en el registro creado sea necesaria para su validez, ni que ello, por sí solo, pueda determinar la naturaleza jurídico-civil de tales disposiciones, ni la del propio registro. Sin embargo, una simple lectura de la norma permite llegar a la conclusión contraria, puesto que dicho precepto expresa con claridad que dicho documento «debe inscribirse en el registro de voluntades digitales», lo que reitera el art. 421-24, al imponer la misma exigencia al referirse a las personas designadas para ejecutar las voluntades digitales del causante.

Desde esta perspectiva, no puede equipararse la eficacia que deriva de la inscripción en el registro creado en la ley de voluntades digitales de Cataluña con la que produce la inscripción en el Registro de actos de última voluntad. Las funciones de este último registro consisten únicamente en la toma de razón del otorgamiento de testamentos y la expedición de certificados de últimas voluntades, amén de la toma de razón de actas de notoriedad de declaración de herederos ab intestato (Bauza Martorell, 2014: 1649). Como es sabido, el certificado de últimas voluntades es el documento que acredita si una persona ha otorgado testamento/s y ante qué notario/s, y permite a los herederos que puedan dirigirse al notario autorizante del último testamento y obtener una copia (autorizada) del mismo, siendo un documento que se precisa para la realización de cualquier acto sucesorio. En este sentido es doctrina consolidada de la DGRN la que considera que dicho certificado tiene una eficacia relativa, en la medida que solo permite acreditar si se otorgó acto de última voluntad, no acreditándose mediante el mismo la condición de heredero ${ }^{49}$.

Junto con ello, el TC entiende que el contenido de la declaración de voluntad expresada en el documento de voluntades digitales sería bastante más amplio del que se le ha querido atribuir, puesto que abarcaría «la decisión sobre el destino que tras la muerte desea dar la persona a su patrimonio digital manifestada al margen de los instrumentos ordenadores de las últimas voluntades conforme al derecho civil aplicable en Cataluña» (FJ 4). Aun cuando pudiera parecer que el TC realiza una interpretación excesivamente amplia del contenido de las voluntades digitales, vinculándolas directamente a las previsiones en relación con el destino de los bienes digitales, siendo así que estas solo alcanzarían a «las disposiciones establecidas por una persona para

49 Así, entre las más recientes, puede citarse la RDGRN, de 19 de diciembre de 2018 (RJ 2017/5840). 
que, después de su muerte, el heredero o el albacea universal, en su caso, o la persona designada para ejecutarlas actúe ante los prestadores de servicios digitales con quienes el causante tenga cuentas activas», es evidente que dicha actuación podría afectar, como señala, al destino de los bienes digitales del causante, en atención a la multiplicidad de supuestos que se contemplan bajo tal denominación. Como ha señalado la doctrina, resulta dudoso que algunos de los contenidos creados por el causante en vida tengan carácter patrimonial y que, por tanto, sean transmisibles mortis causa, pero lo que sí podrían en su caso formar parte de la herencia son las consecuencias jurídicas derivadas del ejercicio de estos derechos (Santos Morón, 2018: 417), así como las relaciones jurídicas contractuales mantenidas con los prestadores de servicios digitales que, por su propia naturaleza o por las estipulaciones en ellas establecidas, no se extingan a la muerte del causante. Por ello, en cuanto a que por medio de la voluntad manifestada por el causante en el documento de voluntades digitales se permite otorgar al designado una legitimación lo suficientemente amplia para una actuación lo suficientemente indeterminada en relación con los bienes digitales del causante a su fallecimiento ${ }^{50}$, cabe considerar adecuada la interpretación que efectúa el TC sobre el contenido y alcance de las voluntades digitales y los efectos que las mismas están llamadas a producir.

En sentido contrario, el voto particular emitido parte de una interpretación ciertamente diferente del contenido de las voluntades digitales, tal como aparece regulado en la Ley 10/2017 de Cataluña. Para la magistrada que lo expresa, el contenido de las voluntades digitales se identifica exclusivamente con la realización de unas actividades muy concretas, que están relacionadas directamente con el ejercicio de derechos personalísimos de carácter no patrimonial y, por tanto, no transmisibles mortis causa $a^{51}$. Por ello, entiende que la formalización del documento de voluntades digitales no introduce un tratamiento jurídico diferente respecto al destino sucesorio de los bienes del causante, ni tan siquiera a los de naturaleza digital, que siguen el destino que este haya marcado en testamento, y a falta de este, en la ley. Pero olvida la magistrada que las voluntades digitales solo tendrán efecto en la sucesión intestada del causante, siendo necesario acreditar que este no ha emitido declaración de voluntad mortis causa en alguna de las formas posibles conforme al derecho catalán para que alcancen eficacia las voluntades digitales. Ciertamente, a falta

50 Si tal actuación no se circunscribe a las actividades enumeradas en la ley, sino que alcanza al contenido que el causante haya querido establecer en el ejercicio de su autonomía de la voluntad, que es la interpretación que parece admitir el TC.

51 Argumento idéntico al expresado por Solé Resina para atribuir carácter meramente administrativo al registro creado. 
de testamento, el destino de los bienes del causante transmisibles mortis causa será el determinado en la ley, y en este caso la ley es la que está determinando la validez de una serie de actuaciones, cuyo alcance concreto no resulta claro, en atención a cierta clase de bienes de naturaleza jurídica diversa, sin establecer precisión alguna, aun cuando específicamente no contemple la previsión de acto de disposición, entendido este en el alcance patrimonial del término.

Por ello, el TC destaca que el valor que ha de otorgase a la declaración de voluntad expresada en las voluntades digitales sería equivalente al que se otorga al testamento, siendo esta la razón por la que, para acceder al registro en el que se inscriban, la norma exigía que se aportara certificado de actos de última voluntad, del que constare que el causante no ha otorgado disposición alguna de esta naturaleza. Se trataría, para el Tribunal, de un documento que surte efecto en la sucesión intestada, a través de la inscripción en el registro electrónico creado al efecto. De ahí que quienes acrediten un interés legítimo puedan solicitar del encargado del registro un certificado relativo a la existencia o no de dichas voluntades, pudiendo extenderse dicha certificación, salvo disposición en contra del causante, a la identificación de la persona encargada para ejecutarlas, siendo la persona designada la única que puede pedir certificación respecto al contenido de tales voluntades digitales.

Puesto que la distinción entre registros jurídicos o de configuración jurídica y los registros meramente administrativos deriva de la proyección de los efectos que generan unos u otros, siendo los primeros aquellos llamados a proyectar sus efectos jurídicos sustantivos sobre las relaciones privadas, mientras que en los segundos la inscripción lo es con el alcance de mera publicidad, el TC destaca que la inscripción en el registro electrónico creado al efecto determina la oponibilidad de este frente a terceros que operan en el tráfico jurídico; oponibilidad que solo decae en el caso de que el causante hubiere otorgado disposición de última voluntad.

De esta forma, el TC admite que la inscripción no lo sería a los meros efectos de publicidad, es decir, a los meros efectos de dar a conocer la existencia de que el causante emitió dicha declaración de voluntad, que es el efecto que produce la inscripción en el Registro de actos de última voluntad, y de ahí su naturaleza de registro meramente administrativo, sino que el efecto propio de la inscripción alcanza eficacia en el tráfico jurídico $(\mathrm{FJ} 4)^{52}$.

Es evidente que esta eficacia se despliega en un doble ámbito: por un lado, frente a los prestadores de servicios digitales, ante los que se podrá hacer valer el contenido de las decisiones adoptadas por el causante; de otro, frente a quienes están llamados a sucederle en el ámbito de la sucesión intestada,

52 En sentido contrario, Solé Resina (2018: 438). 
puesto que si el designado es persona diferente a ellos, su actuación en relación con los bienes del causante, incluso en relación con los que pudieran tener carácter patrimonial, desplaza el ámbito de actuación de los herederos del fallecido a los que, a falta de voluntades digitales, la propia ley les atribuye idéntica función.

Para la magistrada discrepante, el hecho de que las voluntades digitales produzcan efectos al fallecimiento del otorgante y que a tales disposiciones se las denomine de manera similar a las testamentarias no significaría que tengan naturaleza testamentaria, ni que deban custodiarse en un registro civil de los que contempla el art. 149.1.8 de la CE, entendiendo que, aunque así la tuvieran, no existe ningún problema de relación o coexistencia, porque la ley catalana establece la incompatibilidad entre ambos instrumentos y limita la eficacia de las voluntades digitales a falta de este. Creo, sin embargo, que la inconstitucionalidad o no de los preceptos impugnados no se funda en la compatibilidad o no de las voluntades digitales con cualquiera de los negocios jurídicos en los que el causante hubiera podido ordenar su voluntad mortis causa, sino en la eficacia de la propia inscripción en las relaciones interpersonales que, en este específico supuesto, se prevé para después del fallecimiento.

Por último, el TC advierte de que el hecho de que, con posterioridad a la normativa impugnada, el legislador estatal haya regulado en los arts. 3 y 96 de la Ley Orgánica de Protección de Datos las reglas relativas al acceso de los legitimados a los archivos digitales, con expresa mención de que en las CC. AA. con derecho civil propio se estará a lo establecido por estas dentro de su ámbito de aplicación (art. 94.6), no permite sanar la carencia de competencia autonómica en este caso (FJ 4). En virtud del principio de indisponibilidad de las competencias, razona el Tribunal que esta competencia nunca podría entenderse referida a la ordenación de los registros e instrumentos públicos del art. 149.1.8 CE, que ostenta el Estado con carácter pleno, lo que determina que ninguna comunidad autónoma pueda, sin incurrir en inconstitucionalidad, proceder a la creación y regulación de registros jurídicos de carácter civil. Como observa, en esta materia las CC. AA. solo podrían asumir competencias ejecutivas. Argumento que es coherente con la doctrina manifestada por el TC en relación con la competencia sobre esta materia y el alcance de las que hasta la fecha han asumido casi todas las CC. AA., relativa, entre otros, a los registros de la propiedad y civil, registros jurídicos por excelencia.

Por último, hay un aspecto importante que debe resaltarse en la lectura de esta STC, y en concreto del voto particular que se emite, del que entiendo resulta una crítica enmascarada - si no directa - a la doctrina del TC relativa al alcance de la competencia estatal sobre ordenación de los registros e instrumentos públicos, en su aplicación a otros registros creados por las CC. AA. en el ejercicio de competencias asumidas estatuariamente. En concreto, la magis- 
trada Roca i Trias sostiene que, a diferencia de lo decidido en esta sentencia, el TC ha legitimado la competencia autonómica en materias tales como «registros de asociaciones y fundaciones, cuya inscripción es determinante para que las recién constituidas adquieran personalidad jurídica» (sic), admitiendo, pese a ello, su naturaleza administrativa.

$\mathrm{Al}$ margen de lo referido por la magistrada discrepante en orden a la inscripción de las asociaciones, que no adquieren personalidad jurídica por la inscripción registral, sino conforme a lo dispuesto en el art. 5 de la Ley Orgánica $1 / 2002$, de 22 de marzo, esto es, desde el momento mismo en que se otorga el acta fundacional, y sobre las que el TC ya se manifestó acerca del valor que ha de darse a la inscripción a efectos de su constitución ${ }^{53}$, es cierto que su inscripción registral despliega ciertos efectos jurídicos sustantivos en las relaciones privadas. Así, el régimen de responsabilidad que se regula en el art. 10.4 de la citada ley orgánica, norma que, conforme a lo dispuesto en el párrafo $2 .^{\circ}$ de su disposición final primera, es de directa aplicación en todo el Estado, al dictarse al amparo del art. 149.1.1 de la CE. Pues bien, en ella se configura legalmente un régimen de responsabilidad frente a terceros que se aúna directamente a la inscripción registral del ente asociativo, por lo que, en aplicación de la doctrina del TC relativa a la ordenación de los registros, la naturaleza jurídico-pública de los registros de asociaciones resulta cuanto menos dudosa, a menos que se entienda, de una forma excesivamente laxa, que tales efectos son meramente colaterales y no constituyen un argumento suficiente para subsumir tales registros en el ámbito de la competencia estatal ${ }^{54}$.

Junto con ello, es cierto que la eficacia de la inscripción registral respecto a las fundaciones sí alcanza a la adquisición de personalidad jurídica por estas, tal como consta del art. 4.1 de la Ley 50/2002, de 26 de diciembre, de Fundaciones, sin que el TC se haya manifestado respecto a si este efecto jurídico, con evidente alcance en el ámbito de las relaciones jurídicas inter privatos, justifica la asunción de la competencia estatal en la ordenación del registro de fundaciones, como así vienen entendiendo algunos de los autores que han estudiado este tema ${ }^{55}$.

53 STC 133/2006, de 27 de abril (FJ 11) (RTC 133/2006).

54 Como vimos al analizar la doctrina del TC en esta materia, este ha admitido en alguna ocasión que la inscripción registral en algunos registros, a los que se reconoce carácter administrativo, puede producir efectos jurídicos colaterales en el ámbito del derecho privado (STC 11/2015, de 5 de febrero [RTC 11/2015]). Sin embargo, a mi juicio, resulta bastante difícil aplicar esta doctrina al registro de asociaciones, puesto que en este caso concreto sí se produce, como consecuencia de la inscripción, una alteración del régimen jurídico de la responsabilidad de estas frente a terceros.

55 Entre otros, La Casa García (2014). 
De la lectura del voto particular debe destacarse igualmente el paralelismo que la magistrada que lo emite pretende establecer con algunos otros registros creados en otras materias que, a su juicio, afectan al derecho civil de la persona, entre ellos, el de parejas estables de Cataluña, creado por el Decreto Ley 3/2015, de 6 de octubre, y que se regula en la Orden JUS/44/2017, de 28 de marzo $^{56}$, por medio de la cual se aprueba el Reglamento del Registro de parejas estables de dicha comunidad. Sin embargo, en estas normas se observa que el registro creado lo es a los solos efectos de publicidad, sin que la inscripción alcance efectos respecto a la constitución de las uniones creadas, orientándose, igualmente, hacia la satisfacción de los requisitos establecidos por la legislación de la Seguridad Social en lo relativo a la pensión de viudedad (sic). Por ello, a priori, y sin perjuicio de un análisis más exhaustivo, parece que el carácter administrativo que le atribuye el legislador catalán resulta acorde con la doctrina del TC sobre esta concreta materia, que analicé con anterioridad ${ }^{57}$.

La adecuación al régimen de distribución competencial establecida en la CE podría generar mayores dudas en relación con el Registro de nombramientos tutelares no testamentarios, de poderes otorgados en previsión de incapacidad y de patrimonios protegidos, regulado en el Decreto 30/2012, de 13 de marzo, de Cataluña, al que también se refiere el voto particular. Dicha norma se dicta, tal como consta en su preámbulo, en el ejercicio de las competencias que ostenta la comunidad autónoma de Cataluña en derecho civil y en desarrollo de los preceptos que regulan estas materias en el CC de Cat. ${ }^{58}$, y tiene por objeto regular la organización, el funcionamiento y la publicidad de estos registros. Normas que en ningún momento han sido objeto de recurso ante el TC.

56 LCAT 2017/178.

57 STC 81/2013, de 11 de abril (RTC 81/2013).

58 En concreto, el art. 222.8 del libro segundo del CC de Cat., relativo a la persona y la familia, aprobado por la Ley 25/2010, de 29 de julio, dispone que en el Registro de nombramientos tutelares no testamentarios se tienen que inscribir las delaciones de las tutelas otorgadas en escritura pública en uso de las facultades que establecen los arts. 222.4 y 222.5 y también los poderes otorgados en previsión de una situación de incapacidad. Asimismo, en virtud de la disposición adicional primera de la Ley 25/2010, de 29 de julio, se crea el Registro de patrimonios protegidos. En el apartado tercero de esta disposición adicional se prevé que la organización, el funcionamiento y la publicidad de este registro se tienen que establecer por reglamento. 


\section{A MODO DE CONCLUSIÓN}

Expuesto lo anterior, y a modo de conclusión, cabe admitir que ciertamente existe una doctrina constitucional consolidada en relación con el alcance de la competencia estatal ex art. 149.1.8 CC, que viene reiterando el TC en las resoluciones en las que ha tenido que pronunciarse sobre ello. Cuestión diferente es que su aplicación práctica resulte adecuada desde un punto de vista estrictamente técnico en la observación de los temas concretos sobre los que el Alto Tribunal ha debido pronunciarse.

Aun con ciertas imprecisiones, de ella resulta que los registros que han de subsumirse en el ámbito del precepto serán aquellos cuya inscripción despliega efectos jurídicos sustantivos en el ámbito de las relaciones privadas de naturaleza civil, esto es, aquellos registros que gozan de la presunción de integridad y certeza, así como de oponibilidad frente a terceros de lo en ellos publicado en las relaciones privadas, sin descartar totalmente su vinculación a la materia a la que afecta. No obstante, la aplicación concreta de esta doctrina de alcance general en algún caso específico es susceptible de generar dudas respecto a su aplicación uniforme a algunos de los registros creados por las CC. AA. en el ejercicio de competencias que son propias y sobre los que existe pronunciamiento expreso del Alto Tribunal. A mi juicio, ello se observa particularmente en relación con los registros de personas jurídicas; en estos casos, parece que el TC se ha dejado llevar por una cierta inercia histórica en cuanto a la atribución de carácter meramente administrativo a estos registros, que entiendo no resulta del todo adecuada, atendidos algunos de los efectos que derivan de la inscripción.

Es evidente que el alcance específico de esta competencia no es ajeno a la incidencia que puede tener en ello el carácter dispositivo de la justicia constitucional, que puede propiciar actuaciones aleatorias en cuanto a la formulación del oportuno recurso ante el TC. Ello conlleva la ausencia de pronunciamientos expresos sobre la adecuación a la CE de algunos de los registros creados por las CC. AA. en el ejercicio de competencias que les son propias. Junto con ello, es evidente que los pronunciamientos del TC se encuentran condicionados al contenido del propio recurso y al alcance con el que este se formule, lo que genera cierta inseguridad al intérprete al analizar el contenido de sus resoluciones.

A la vista de la doctrina constitucional sobre la competencia estatal relativa a la ordenación de los registros e instrumentos públicos, entiendo que resulta acertada la aplicación que de esta se realiza en relación con el registro de voluntades digitales creado por la comunidad autónoma de Cataluña. La lectura de la STC 7/2019, de 17 de enero, permite concluir que el TC destaca en ella la eficacia que la inscripción estaba llamada a producir y la naturaleza 
jurídico-privada de estos efectos, aun cuando no se desvincule totalmente de la materia a la que afectan.

\section{Bibliografía}

Bauza Martorell, F. J. (2014). El registro de actos de última voluntad. Problemas de legitimación y acceso. En O. Monje Balmaseda (coord.), F. Lledó Yague, M. P. Ferrer Vanrell y J. A. Torres Lana (dirs.). El patrimonio sucesorio: reflexiones para un debate reformista (pp. 1647-1662). Madrid: Dykinson.

Cámara Lapuente, S. (2019). La sucesión mortis causa en el patrimonio digital: una aproximación. El Notario del Siglo XXI, 84.

Chico Ortiz, J. M. (1982). La penetración del derecho público en el derecho privado: su reflejo constitucional y la repercusión en el derecho registral. Revista Crítica de Derecho Inmobiliario, 58 (552), 1167-1188.

De Pablo Contreras, P. (1999). La «Legislación Civil» y la competencia autonómica en materia de asociaciones. Repertorio Aranzadi del Tribunal Constitucional, 1, 1831-1844.

García Herrera. V. (2018). Disposición mortis causa del patrimonio digital. Diario La Ley, 9315.

García Rubio, M. P. (2017). Presente y futuro del Derecho civil español en clave de competencias normativas. Revista de Derecho Civil, 4 (3), 1-33. Disponible en: https://bit.ly/2kNqTeU.

Gimeno y Gómez-Lafuente, J. L. (1982). La ordenación de los Registros e instrumentos públicos en la Constitución española de 1978. Revista Crítica de Derecho Inmobiliario, 552, 1309-1338.

Ginebra Molins, M. E. (2018). Morir en la era digital: «Voluntades digitales», intimidad y protección de datos personales. En M. J. Blanco Sánchez (coord.) y A. Madrid Parra (dir.). Derecho mercantil y tecnología (pp. 107-153). Pamplona: Aranzadi.

González Granados, J. (2015). La herencia digital: Nadie posteará por nosotros cuando estemos muertos. Taller de Derechos, 9 de marzo de 2015. Disponible en: https://bit.ly/2lSYDb4.

La Casa García, R. (2014). La publicidad registral de las fundaciones y el registro mercantil. Revista de Derecho Mercantil, 292, 121-176.

Leyva de Leyva, J. A. (1989). Planteamiento general de los registros públicos y su división en registros administrativos y registros jurídicos. Revista Crítica de Derecho Inmobiliario, 5 (591), 261-308.

Marín López, J. J. (1994). La ordenación de los registros e instrumentos públicos como título competencial del Estado. Derecho Privado y Constitución, 2, 111196. 
Pérez Escalona, S. (2006). Constitucionalidad de la Ley Orgánica de Asociaciones y reparto de competencias normativas en materia de asociaciones. Repertorio Aranzadi del Tribunal Constitucional, 8, 11-28.

Prados Ramos, L. (2014). La herencia digital. Problemas y soluciones en el Derecho de Catalunya. Disponible en: https://bit.ly/2lXYOli.

Ruiz-Rico Ruiz, J. M. y Casado Casado, B. (2004). Las uniones de hecho no matrimoniales: consideraciones generales y aspectos registrales. Revista Crítica de Derecho Inmobiliario, 80 (685), 2307-2378.

Santos Morón, M. J. (2018). La denominada «herencia digital». ¿ Necesidad de regulación? Estudio de Derecho Español y Comparado. Cuadernos de Derecho Transaccional, 10 (1), 413-438. Disponible en: https://doi.org/10.20318/ cdt.2018.4128.

Solé Resina, J. (2018). Las voluntades digitales: marco normativo actual. Anuario de Derecho Civil, 71 (2), 417-440. 